\title{
SELF-PERCEIVED HEALTH IN THE CZECH POPULATION: RECENT EVIDENCE
}

\author{
Olga Kurtinová \\ Institute of Sociology of the Czech Academy of Sciences, Prague, Czech Republic
}

\begin{abstract}
SUMMARY
This article considers developing trends in self-perceptions of health among the Czech population. Its conclusions are based on data from the European Union Statistics on Income and Living Conditions (EU-SILC) conducted from 2005-2011. The data analysis suggests that the compression of morbidity is present, but the Czech Republic continues to lag behind Western Europe. In addition, among males the difference in health expectancies between the Czech Republic and the EU-15 is due to a change in mortality at higher ages, rather than in self-perceived health. Among females the opposite is true. Demographic categories, such as "attained education" and "age-group" proved to be significant factors in influencing self-perceived health in the Czech population for the year 2011. Gender and marital status seem to be less important.
\end{abstract}

Key words: self-perceived health, Sullivan method, EU-SILC, Czech Republic

Address for correspondence: 0 . Kurtinová, Institute of Sociology of the Czech Academy of Sciences, Value Orientations in Society, Jilská 1, 11000 Prague 1, Czech Republic. E-mail: olga.sivkova@soc.cas.cz

\section{INTRODUCTION}

Significant improvements in life expectancy at birth, which measures the average lifespan of a person born in a given year if mortality levels remain constant, have continued over the last few decades. In fact, this improvement has been documented in most regions throughout the world $(1,2)$. Advances in medicine and public health, improved living standards, higher levels of education attainment, and lower levels of fertility are considered to be the key contributing factors in this change. While this greater life expectancy at birth is generally considered to be good, it raises new questions. In the 1980s three theoretical concepts about the relationship between mortality and morbidity were formulated. The first concept states that the compression of morbidity, which follow medical progress, leads to a reduction of years spent in bad health (3). The second concept states the opposite, the extra years of life gained through increased longevity are spent in bad health (4-6). The third concept strikes a dynamic equilibrium between the first two. Manton (7) claims that the proportion of years spent in good and bad health remains constant, even as life expectancy at birth increases. Clarifying which conception holds the most truth will contribute to our knowledge of quality of life at older ages, can increase the efficiency of health care, and possibly reduce the financial burden of the health care system.

Population health and its measurement has become a crucial issue these days, especially among ageing societies in developed countries. For instance, the European Union integrated population health into its list of structural indicators. It now monitors the progress and efficiency of implemented policies and measures its population's health based on life expectancy (using the metric of Healthy Life Years, HLY). Although it is reasonable to assume that an association between mortality and morbidity exists, one simple summary indicator of population health does not exist due to the many dimensions of health and various methods of calculation.
According to the WHO definition, health is a state of complete physical, mental, and social well-being and not merely the absence of disease or infirmity (8). The basic summary measures of population health are divided into health gaps and health expectancies. While health gaps quantify the difference between a present and an ideal situation (e.g. Disability-adjusted Life Years, Years of Life Lost, Years Lived with Disability, Potential Years Lost), health expectancies add quality dimensions to the standard measure of life expectancy. The two sub-divisions of health expectancies, according to calculation methods, are Health State Expectancy (HSE) and Health-adjusted Life Expectancy (HALE). Of these two, Health State Expectancy can be based on perceived health, morbidity or disability, reflecting limitations in daily activities (9).

However, while hundreds of papers deal with health expectancies, only a few examine data from the Czech Republic. Salomon et al. (1) reports the Healthy life expectancy for 187 countries, including the Czech Republic, for the period 1990-2010. In spite of the fact that the article focuses on overall trends in world regions rather than on one specific country, based on the presented data it seems that the compression of morbidity holds for the Czech population in terms of disability. In comparison with that, Jagger et al. (10) examines the inequalities of health expectancies in the 25 countries of the European Union. The findings suggest that healthy life expectancies vary more between countries than life expectancy, and that the level of health expectancy in European countries is positively associated with the gross domestic product and expenditure on elderly care. In-depth analysis of the Czech data can be found in the work of Rychtaríková $(11,12)$, Hrkal (15) and Hrkal et al. (16). Rychtaříková (12) documented similar phenomena observed in other countries using data from the Generation and Gender Survey (GGS) (13) and showed that different social groups of the Czech population are affected by various maladies and conditions. While males have shorter lives, women spend their extra years in illness or with limitations in everyday 
activities. In addition, good health was negatively associated with age and positively with education. In terms of family relations, partnership was more important for those in bad health (12).

Considering these classification, this article focuses on the development of health state expectancies in the Czech population, taking into account self-perceived health. Because perceived health is a result of self-assessment, and therefore not necessarily connected to a certified diagnosis, this article also examines sociodemographic factors which influence recent developing trend in the Czech population. Statements about self-perceived health are influenced by gender, age, family relationships, attained education, environment, life-style, economic activity, etc. To explore the possible effects of these factors, the model of multinomial logistic regression is employed for the individual data from the European Union Statistics on Income and Living Conditions (EU-SILC) 2011.

\section{MATERIALS AND METHODS}

Self-perception of health can be difficult to interpret due to subjectivity and the disconnection between perceived and actual health. Nonetheless, it appears in many surveys of general health. Table 1 provides an overview of data sources available for the Czech Republic. The list consists of ten fundamental reports for various years available. In theory, it was possible to construct a time series of self-perceived health from the beginning of the 1990 's, but in practice the issue of comparability emerged, as the surveys' methodologies were not consistent. Therefore, this article uses only data from the EU-SILC conducted from 2005-2011. An advantage of this data set is its comparability within time and among countries. Furthermore, individual data was available for 2011 to study the influence of socio-demographic factors on selfperceived health in the Czech Republic (Table 4).

The EU-SILC has been one of the largest recent surveys conducted by Eurostat which is compulsory for the member states of the European Union. The project was introduced in seven countries (Belgium, Denmark, Greece, Ireland, Luxembourg, Austria, and Norway) in 2003, and today provides cross-sectional and longitudinal microdata or aggregate data on income, poverty, social exclusion and living conditions in Europe. The output harmonization strategy is adopted to ensure data comparability among states. The health module of this survey is not so large in comparison to surveys primarily focused on health, but it does include three questions on general health status and four questions about unmet needs in health care (14). These questions about general health status provide information about self-perceived heath, chronic (long-lasting) illnesses, and the limitation of activities. It is with these factors that the previously mentioned Healthy Life Years (HLY) is calculated. In order to link results among European surveys, the questions create a so-called Minimum European Health Module (MEHM).

Data on self-perceived health (SPH) does not reflect any temporary health problem but pertains to the respondent's self-assessment of his or her general health state using a scale from "good" to "fair" to "bad". Although an assessment of self-perceived health does not necessarily reflect a respondent's real state of health, which would be stated by physician, it does provide important information about quality of life. The population covered is 16 years and older. Except for the individual data set of the EU-SILC 2011 for the Czech Republic (Table 4), data from the EurOhex database was used. This database belongs to the European Health and Life Expectancy Information System (EHLEIS), which is a joint project of the European Commission and Member states of the EU. The programme was launched in 2011, but the roots of the initiative go back to 1990's when the EURO-REVERS was set up in 1994 (19). Not long afterward, the projects of the European Health Expectancy Monitoring Unit (EHEMU, 2004-2007) and EHLEIS (2007-2011) were established. The main objective of the programmes has been to improve methodology in terms of data collection and calculations of health expectancies. It is worthwhile to note that not only European countries carry out research into health expectancies, but the interest is worldwide.

Health expectancies presenting the remaining number of years spent in good and bad health have now become broadly accepted as an indicator of population health, but it is necessary to note that there are many health expectancies due to the multi-dimensional nature of health and various methods of calculation. Basically three methods for calculating health expectancies are used: a double decrement life table, a multi-state life table, and a Sullivan's method (17). The double decrement life table considers changes in the number of survivors due to health problems and death. The multi-state life table is an extension of the first, where individuals under observation move from one state to another, e.g. from

Table 1. Overview of surveys that provide data about the self-perceived health of the Czech population

\begin{tabular}{|c|c|}
\hline Survey name & Years available \\
\hline World Values Survey & 1991, 1995 \\
\hline European Values Study & 1990,2008 \\
\hline Social Situation of Households* & 2001 \\
\hline Eurobarometer & 2006 \\
\hline European Social Survey (ESS) & $2002,2004,2008,2010$ \\
\hline Generation and Gender Survey (GGS) & 2005,2008 \\
\hline International Social Survey Programme (ISSP) & 2011 \\
\hline Survey of Health, Ageing and Retirement in Europe (SHARE) & $2006,2008 / 9,2010$ \\
\hline Sample Survey of the Health Status of the Czech Population (HIS)/European Health Interview Survey (EHIS) & $1993,1996,1999,2002,2008$ \\
\hline EU-Statistics on Income and Living Conditions (EU-SILC) & 2005-2011 \\
\hline
\end{tabular}

*Survey conducted by the Czech Statistical Office, methodology reflected the European Community Household Panel (ECHP) 
healthy to chronic illness to disability or the other way around $(17,18)$. These methods are advanced demographic methods and therefore, in comparison with the last method, Sullivan's method, require detailed longitudinal data. Sullivan's method, which is also utilized in this article, is the most frequently applied method because of its simplicity and limited data requirements. This method combines mortality, based on conventional life tables, and a prevalence ratio of health states (20). The essence of the method may be expressed as follows:

$$
e_{x, i}=\left[\Sigma\left(s_{x, i} * L_{x}\right)\right] / l_{x},
$$

where $e_{x, i}$ presents the average number of years lived by a person from exact age $\mathrm{x}$ in health status $\mathrm{i}$ (healthy life expectancy of health status i), $L_{x}$ is the number of person-years lived in the interval between exact ages $\mathrm{x}$ and $\mathrm{x}+\mathrm{n}, \mathrm{s}_{\mathrm{x}, \mathrm{i}}$ denotes a prevalence ratio of health status $i$ among individuals at age $x$, and $1_{x}$ equals the number alive at exact age $\mathrm{x}$. Commonly, health expectancies are calculated separately for men and women at ages 0 and 65 . The disadvantage of this method is that it reflects past health risk factors, rather than present ones, because it is based on transversal data. Although the multi-state method profoundly differs from Sullivan's method, according to the literature it seems that both methods provide similar and reliable results (21).

To decompose the difference in health expectancy a modified form of Arriaga's algorithm according to Nusselder et al. (22) is applied. While Arriaga's approach estimates extra years gained/ lost to life expectancy in a given age group due to decrease/increase in the central mortality rate, the extended method allows for estimates of what number of extra years in a given age-group is due to mortality and morbidity. The method's assumption is that health expectancy is calculated based on Sullivan's approach.

\section{Self-perceived Health and Health Expectancies in the Czech Population}

Without a doubt, one of the fundamental determinants of health is age. Figure 1 shows the prevalence ratio of self-perceived health by gender for the Czech Republic in 2011. The trend of increasing age coinciding with decreasing opinions of health is obvious. This association is plausible because ailments occur more frequently with age and therefore the shift from good to fair or bad self- perceived health is more probable. Till the age of 75 , more than $80 \%$ of men and $73 \%$ of women stated their health as good or fair in 2011. Afterwards the proportion of people who perceive their state of health as bad significantly increases. For the age-group $80-84$ years almost $38 \%$ of men and $47 \%$ of women describe their health status as bad in a given year. From the data it is also obvious that men view their state of health more positively than women. Overall age-group prevalence ratios of bad self-perceived health for males are lower than for females. When the data from 2005-2011 is considered, similar trends in prevalence ratios for both men and women are present.

A comparison of prevalence ratios in time reveals remarkable phenomena regardless of gender. In the case of males, the agegroups 60-64 and 65-69 for the period 2005-2010 declared their general health as good and fair more often than the age-group 55-59. For females a similar pattern can be seen in the data, but it holds for the age group 50-59 and 60-64 years in comparison with the age-group 50-54 years. The findings suggest that, taking into account retirement age in the Czech Republic (24), individuals at early stages of retirement feel better than those who still have a few years until retirement. The question arises whether insecurity in the labour market could influence this feeling, because in general the unemployment rate of older persons is relatively higher than that of their younger counterparts. Figure 1, based on data from 2011, shows a different pattern of prevalence ratios. Better selfperceived health is present in the age-group of 65-69 year-old men and in the age-group of 60-64 year-old women when compared to the previous age-group. The difference could be caused by changes in the pension system, which has contributed to general economic uncertainty in the Czech Republic.

In 2011, the life expectancy at birth for men and women was 74.7 and 80.7 years, respectively. Over the last twenty years life expectancy for both men and women increased in the Czech Republic. This trend is partly documented in Table 2, which shows life expectancy at 65 years of age by gender for the period from 2005-2011. While life expectancy at age 65 increased for men by 1.2 years from 2005-2011, for women the increase was slightly higher, 1.5 years. The basic decomposition of difference in life expectancies at age 65 by gender for the years 2005 and 2011 revealed that mortality decreased significantly at higher ages. While the age group of men 65 years-old and older contributed
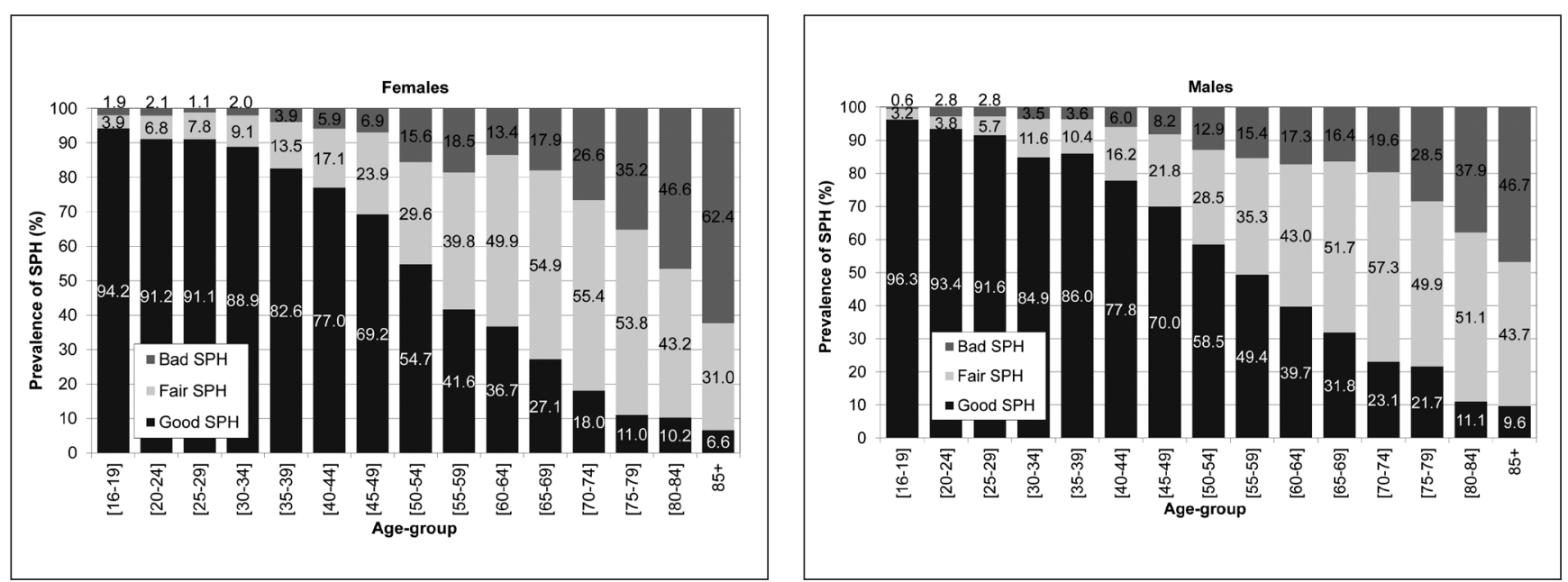

Fig. 1. Prevalence ratio of self-perceived health (SPH) by gender, Czech Republic, 2011.

Source: EurOhex, EU-SILC 
$50 \%$ of the increase in life expectancy, for women it was almost $75 \%$ of the increase. These findings are not surprising, as infant mortality, which markedly influenced life expectancy in past centuries, is now quite low and has no significant impact on life expectancy in the Czech Republic.

Table 2 also shows the distribution of life expectancy at age 65 according to self-perceived health in the period 2005-2011. Except for the bad self-perceived health among males, healthy life expectancies are higher in 2011 than in 2005, which correspond to the above-mentioned development in life expectancy. In 2011, a 65 year-old man living in the Czech Republic could expect that, of 15.6 remaining years, 11.6 years are going to be spent in health and 4 years in illness, ceteris paribus. In the case of women, of the remaining 19.2 years at age $65,12.6$ years will be in good health and 6.2 years in bad health. So, the majority of remaining years both for men and women will be spent in health. The relative numbers in Table 2 confirm not only that men describe their health more positively than women, but also confirm that regardless of gender, relative gains were obtained in favour of good self-perceived health at the expense of bad self-perceived health. Because summary measures consist of various cohorts, results can be influenced by cohort effects (younger cohorts can be objectively healthier) and/or by the fact that external conditions could change positively. Although logistic-regression in the following part of the article deals with socio-demographic factors, due to the factors comprehensiveness it is almost impossible to disentangle their contributions.

Looking at it from a different angle, regardless of the changes in gender distribution in the remaining years, perceived health status was determined by good self-perceived health, especially in younger ages. It is interesting that there is no difference by gender, as Figure 2 shows in the year 2011. The curves representing life expectancy in good health by age are the same both for males and females. In addition, between ages 18 and 50 the number of years in good health and the total number of years decrease linearly and in parallel. Afterwards, the slope of decrease decelerated for both curves. According to Figure 2, the remaining years in bad health change with age only moderately. Therefore, with increasing age and decreasing life expectancy, the weight of the number of years lived in bad health increases. The different attitude of men and women towards self-perceived health is also present in the difference between remaining years in good and bad health respectively. Data for the gender gap in good and bad self-perceived health shows an average difference of 2.8 years and 0.4 years respectively after age 50 . An interesting pattern is present in the remaining years in fair health by gender. Both genders' curves are characterised by a similar convergence as the life expectancy by gender curves. Furthermore, after age 70 there is a marginal gender gap in the difference of life expectancy in bad self-perceived health.

Though life expectancy and health expectancy in good health increased in recent years in the Czech Republic, and though the data suggests that the compression of morbidity is present, the Czech Republic remains far behind the EU-15 (Austria, Belgium, Denmark, Finland, France, Germany, Greece, Ireland, Italy, Luxembourg, the Netherlands, Portugal, Spain, Sweden, and the United Kingdom). Figure 3 shows the association between life expectancy and health expectancy in good and fair self-perceived health at age 65 in European countries in 2010. For both men and women two clusters emerged. In older EU countries, there

Table 2. Life expectancy (LE) and health expectancies based on Self-Perceived Health (LE in SPH) at age 65, Czech Republic, 2005-2011

\begin{tabular}{|c|c|c|c|c|c|c|c|}
\hline & \multicolumn{7}{|c|}{ Males } \\
\hline Year & Life expectancy & LE in good SPH & LE in fair SPH & LE in bad SPH & $\begin{array}{c}\text { LE in good SPH } \\
(\%)\end{array}$ & $\begin{array}{c}\text { LE in fair SPH } \\
(\%)\end{array}$ & $\begin{array}{c}\text { LE in bad SPH } \\
(\%)\end{array}$ \\
\hline 2005 & 14.4 & 2.3 & 7.5 & 4.6 & 15.9 & 52.3 & 31.8 \\
\hline 2006 & 14.8 & 2.8 & 7.3 & 4.7 & 18.7 & 49.4 & 31.9 \\
\hline 2007 & 15.1 & 3.0 & 7.7 & 4.5 & 19.7 & 50.6 & 29.7 \\
\hline 2008 & 15.3 & 3.0 & 7.1 & 5.3 & 19.4 & 46.2 & 34.4 \\
\hline 2009 & 15.2 & 3.2 & 7.6 & 4.4 & 20.7 & 50.1 & 29.1 \\
\hline 2010 & 15.5 & 3.2 & 8.0 & 4.2 & 20.9 & 51.6 & 27.5 \\
\hline \multirow[t]{2}{*}{2011} & 15.6 & 3.5 & 8.1 & 4.0 & 22.4 & 51.8 & 25.8 \\
\hline & \multicolumn{7}{|c|}{ Females } \\
\hline Year & Life expectancy & LE in good SPH & LE in fair SPH & LE in bad SPH & $\begin{array}{c}\text { LE in good SPH } \\
(\%)\end{array}$ & $\begin{array}{c}\text { LE in fair SPH } \\
(\%)\end{array}$ & $\begin{array}{c}\text { LE in bad SPH } \\
(\%)\end{array}$ \\
\hline 2005 & 17.7 & 2.5 & 8.8 & 6.4 & 13.9 & 49.8 & 36.3 \\
\hline 2006 & 18.3 & 2.4 & 8.8 & 7.2 & 12.9 & 48.0 & 39.1 \\
\hline 2007 & 18.5 & 2.8 & 8.9 & 6.9 & 14.8 & 47.9 & 37.3 \\
\hline 2008 & 18.8 & 2.7 & 8.7 & 7.4 & 14.5 & 46.0 & 39.5 \\
\hline 2009 & 18.8 & 3.1 & 8.6 & 7.1 & 16.6 & 45.6 & 37.8 \\
\hline 2010 & 19.0 & 3.3 & 8.8 & 7.0 & 17.3 & 46.1 & 36.6 \\
\hline 2011 & 19.2 & 3.1 & 9.5 & 6.7 & 15.9 & 49.3 & 34.8 \\
\hline
\end{tabular}




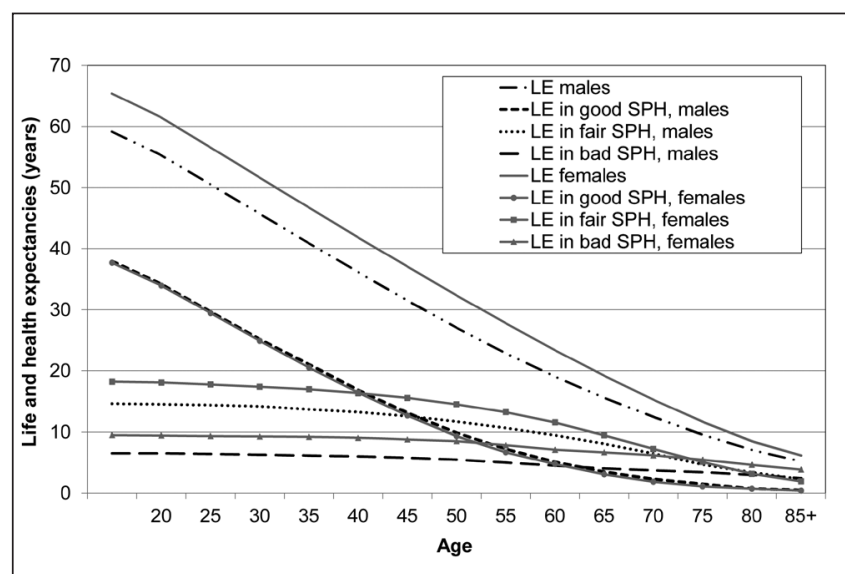

Fig. 2. Life expectancy (LE) and health expectancies based on Self-Perceived Health (LE in SPH) by age and gender, Czech Republic, 2011

Source: EurOhex, EU-SILC

are clusters divided by gender where high life expectancy at 65 matches a larger number of remaining years in good and fair health. The new member states, however, are more dispersed and have lower life expectancies at 65 and fewer years spent in good and fair health.

Obvious exceptions to this trend are Malta and Cyprus, both of which lie in the same clusters as older EU countries. This pattern is not so surprising, as, in addition to other factors, these countries often have a healthier Mediterranean diet and lifestyle which can contribute positively to life expectancy, at least in comparison to Eastern European diet and lifestyle $(26,27)$. Another exception is Portugal, which has more in common with new EU member states. Life expectancy at 65 is higher in Portugal for both men and women than in the new member states, but the number of years spent in good and fair health is significantly lower in comparison to Western European countries. It is difficult to blame this difference on one factor, but it is reasonable to assume that this figure could be influenced by an overall lower satisfaction with life due to the impact of the economic recession that has significantly affected Portugal in recent years. If we focused on the position of the Czech Republic in Figure 3, the country lies within the cluster of new member states, but it has substantially higher life expectancies than others in that cluster. For both males and females, the Czech population lies in the middle of the entire data set.

Table 3. Multinomial logistic regression for the reference category good self-perceived health by gender, Czech Republic, 2011

\begin{tabular}{|c|c|c|c|c|c|c|c|c|}
\hline \multirow{4}{*}{ Predictors } & \multicolumn{8}{|c|}{ Self-perceived heath (SPH, dependent variable) } \\
\hline & \multicolumn{2}{|c|}{ Fair SPH } & \multicolumn{2}{|c|}{ Bad SPH } & \multicolumn{2}{|c|}{ Fair SPH } & \multicolumn{2}{|c|}{ Bad SPH } \\
\hline & \multicolumn{4}{|c|}{ Males } & \multicolumn{4}{|c|}{ Females } \\
\hline & $\operatorname{Exp}($ Coeff.) & Sig. & Exp (Coeff.) & Sig. & Exp (Coeff.) & Sig. & Exp (Coeff.) & Sig. \\
\hline \multicolumn{9}{|l|}{ Marital status } \\
\hline Single & 0.723 & 0.009 & 1.210 & 0.235 & 0.810 & 0.104 & 1.080 & 0.706 \\
\hline Widowed & 0.921 & 0.453 & 0.948 & 0.730 & 1.025 & 0.777 & 1.647 & 0.000 \\
\hline Divorced & 1.358 & 0.077 & 2.140 & 0.000 & 1.396 & 0.000 & 2.047 & 0.000 \\
\hline Married & 1 & & 1 & & 1 & & 1 & \\
\hline \multicolumn{9}{|l|}{ Education } \\
\hline Basic & 1.369 & 0.060 & 2.476 & 0.000 & 2.205 & 0.000 & 6.292 & 0.000 \\
\hline $\begin{array}{l}\text { Secondary without A-level } \\
\text { examination }\end{array}$ & 1.421 & 0.002 & 2.091 & 0.000 & 1.666 & 0.000 & 3.168 & 0.000 \\
\hline $\begin{array}{l}\text { Secondary with A-level } \\
\text { examination }\end{array}$ & 1.213 & 0.090 & 1.095 & 0.617 & 1.219 & 0.062 & 1.719 & 0.006 \\
\hline Higher education & 1 & & 1 & & 1 & & 1 & \\
\hline \multicolumn{9}{|l|}{ Age } \\
\hline $18-29$ & 0.026 & 0.000 & 0.012 & 0.000 & 0.032 & 0.000 & 0.007 & 0.000 \\
\hline $30-49$ & 0.128 & 0.000 & 0.099 & 0.000 & 0.083 & 0.000 & 0.038 & 0.000 \\
\hline $50-69$ & 0.442 & 0.000 & 0.35 & 0.000 & 0.408 & 0.000 & 0.208 & 0.000 \\
\hline $70+$ & 1 & & 1 & & 1 & & 1 & \\
\hline \multicolumn{9}{|l|}{ Income quartile } \\
\hline $1 \mathrm{st}$ & 3.041 & 0.000 & 6.279 & 0.000 & 1.708 & 0.000 & 3.126 & 0.000 \\
\hline 2nd & 2.418 & 0.000 & 3.743 & 0.000 & 1.864 & 0.000 & 2.129 & 0.000 \\
\hline $3 r d$ & 1.376 & 0.002 & 1.593 & 0.011 & 1.34 & 0.001 & 1.779 & 0.000 \\
\hline 4th & 1 & & 1 & & 1 & & 1 & \\
\hline
\end{tabular}

Bold font corresponds to parameter significance at the 0.05 level.

Source: EU-SILC 2011 for the Czech Republic 
Table 4. Distribution of data set by gender, EU-SILC 2011, population at the age 18+, Czech Republic

\begin{tabular}{|c|c|c|c|}
\hline Self-perceived health & Male & Female & Total \\
\hline Good & 3,161 & 3,962 & 7,123 \\
\hline Fair & 1,649 & 2,500 & 4,149 \\
\hline Bad & 709 & 1,142 & 1,851 \\
\hline Total & 5,519 & 7,604 & 13,123 \\
\hline \multicolumn{4}{|l|}{ Marital status } \\
\hline Single & 1,256 & 1,007 & 2,263 \\
\hline Widowed & 568 & 1,043 & 1,611 \\
\hline Divorced & 287 & 1,413 & 1,700 \\
\hline Married & 3,408 & 4,141 & 7,549 \\
\hline Total & 5,519 & 7,604 & 13,123 \\
\hline \multicolumn{4}{|l|}{ Education } \\
\hline Basic & 447 & 1,385 & 1,832 \\
\hline Secondary without A-level examination & 2,536 & 2,443 & 4,979 \\
\hline Secondary with A-level examination & 1,711 & 2,909 & 4,620 \\
\hline Higher education & 824 & 861 & 1,685 \\
\hline Missing & 1 & 6 & 7 \\
\hline Total & 5,519 & 7,604 & 13,123 \\
\hline \multicolumn{4}{|l|}{ Age } \\
\hline $18-29$ & 713 & 789 & 1,502 \\
\hline $30-49$ & 1,721 & 2,359 & 4,080 \\
\hline $50-69$ & 2,204 & 3,011 & 5,215 \\
\hline $70+$ & 881 & 1,445 & 2,326 \\
\hline Total & 5,519 & 7,604 & 13,123 \\
\hline \multicolumn{4}{|l|}{ Income quartile } \\
\hline $1 \mathrm{st}$ & 1,392 & 1,916 & 3,308 \\
\hline 2nd & 1,318 & 2,064 & 3,382 \\
\hline $3 \mathrm{rd}$ & 1,403 & 1,706 & 3,109 \\
\hline 4th & 1,403 & 1,900 & 3,303 \\
\hline Missing & 3 & 18 & 21 \\
\hline Total & 5,519 & 7,604 & 13,123 \\
\hline
\end{tabular}

Decomposition of the difference in life expectancy in good and fair health by age between the EU-15 and the Czech Republic in 2010 revealed the great contribution of both men and women of older age groups (Figure 4). In addition, the total difference in life expectancies in good and fair health is 5.6 years for men, while 3.0 years are due to mortality and 2.6 years to health. For women, the total difference in life expectancies in good and fair health is 5.3 years, while 1.8 years are due to mortality and 3.5 years to health. The results indicate that the Czech Republic may catch up to the EU-15 by improving mortality for elderly people, especially men. A closer look at the decomposition by gender shows that men $55-59$ contribute almost $10 \%$ ( 0.5 years) to the total difference. This corresponds with the fact that individuals in the early stage of retirement feel better than those who still have a few years left to work. For women, the population over 70 contributes the most, i.e. $79 \%$ of the total difference in life expectancy in good and fair self-perceived health. In addition, $63 \%$ of this difference is caused by declared health, which means that women in the Czech Republic perceived their health as worse than women in the EU-15. This begs the question of what could be done to reduce the difference. But that is not a simple question, as self-perceived health is a concept which is also culturally conditioned, and it is reasonable to assume that socio-economic conditions of elderly people in the Czech Republic influence these perceptions.

\section{Factors Associated with Self-perceived Health}

To examine the determinants of self-perceived health in the Czech population, multinomial logistic regression is implemented on the latest available data. The main research question is whether there are differences in perceived health that follow socio-economic factors such as gender, marital status, attained education, age, and net monthly income. According to the literature and the results of descriptive statistics, it is hypothesized that there is a difference between men and women. While women have higher 


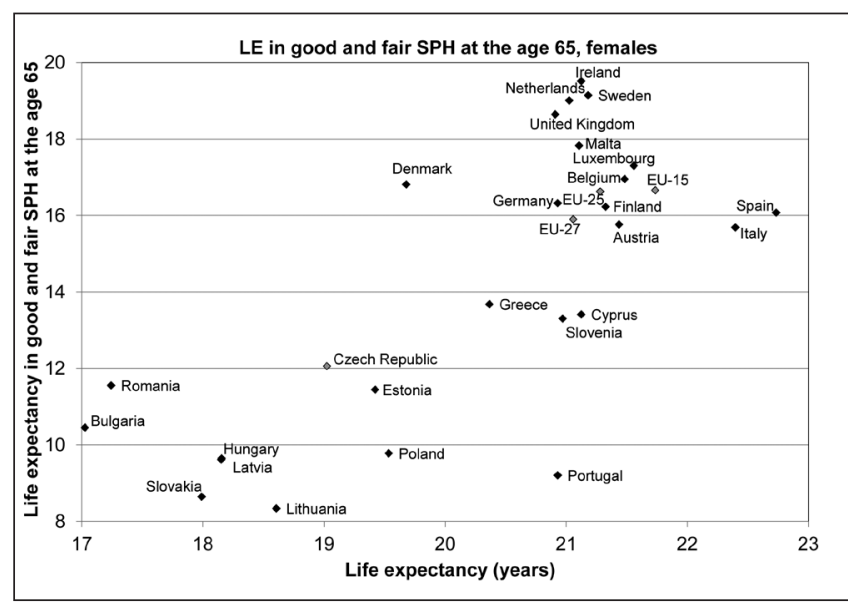

Fig. 3. Life expectancy in good and fair self-perceived health (SPH) by gender at age 65, European Union, 2010.

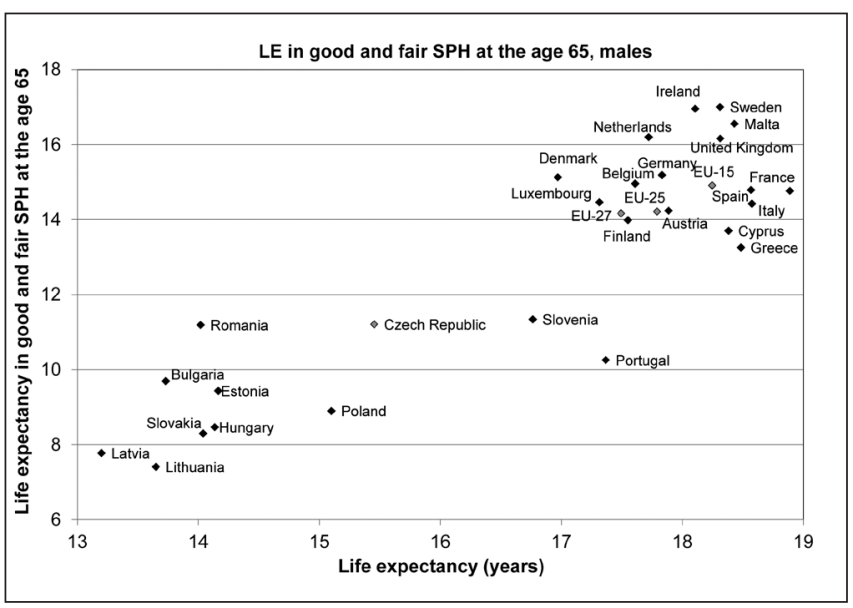

Source: EurOhex, EU-SILC 2010

rates of morbidity and lower rates of mortality, among men the reverse is true. Furthermore, it is assumed that family and partnership has a positive effect on the self-perception of health, and it is assumed that the higher the level of attained education, the better the self-reported health. The effect of age is relatively apparent, because it is universally recognized that a negative relationship exists between them. In terms of income, it is assumed that those with higher income also perceive their health to be better.

To verify the presumptions listed above, individual data from the EU-SILC 2011 for the Czech Republic is analysed (Table 4). The dependent variable is self-perceived health, which is reported in terms of "good", "fair", and "bad". Because marital status enters into the analysis, and only under certain circumstances is a person of 16 or 17 allowed to marry in the Czech Republic, the analysed data corresponds to people aged 18 and over, as they face no legal restrictions on marriage. The total population comprises 13,123 individuals where $42 \%$ are male and $58 \%$ are female. Furthermore, four marital statuses are recognized: single, married, divorced, and widowed. This sample survey data by marital status does not violate known patterns in vital statistics which study population, although the shares do differ slightly. Within the sample, $57 \%$ of individuals are married, $17 \%$ are single, $13 \%$ are divorced, and the rest are widowed. Considering attained education and age, for simplicity's sake the original variables are grouped into four

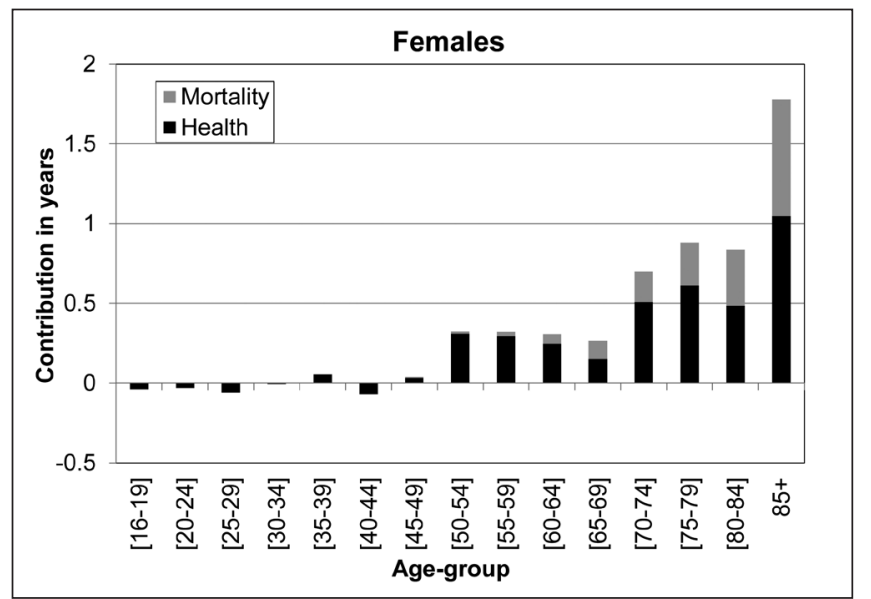

clusters respectively. Levels of attained education consist of the categories basic education, secondary education without A-level examination, secondary education with A-level examination, and higher education. Age groups are divided as follows: 18-29, $30-49,50-69$ and $70+$. The distribution of analysed data is presented in more detail in Table 4. The last predictor included in the model is the quartile of net monthly income in Czech Crowns (CZK). The mean and median net monthly income is $17,504 \mathrm{CZK}$ and 14,460 CZK for men and 12,345 CZK and 11,000 CZK for women, respectively. The gender gap in net income is obvious in this data. In addition, it is assumed that the variable of income approximates the working status of the person. Participation of a person in the labour market was also considered as a predictor, but over the course of data processing the variable proved insignificant. ences is applied separately to each gender. For both models, the model fitting information showed that the regression coefficients in the model are different to zero and that chosen predictors improve estimates in comparison with the model where an intercept predicts the outcome variable only. Table 3 shows the main results. The reference category is good self-perceived health.

The results verify the well-known relationship between falling health status and age. The higher the age, the less likely the
The multinomial logistic regression used to examine differ-

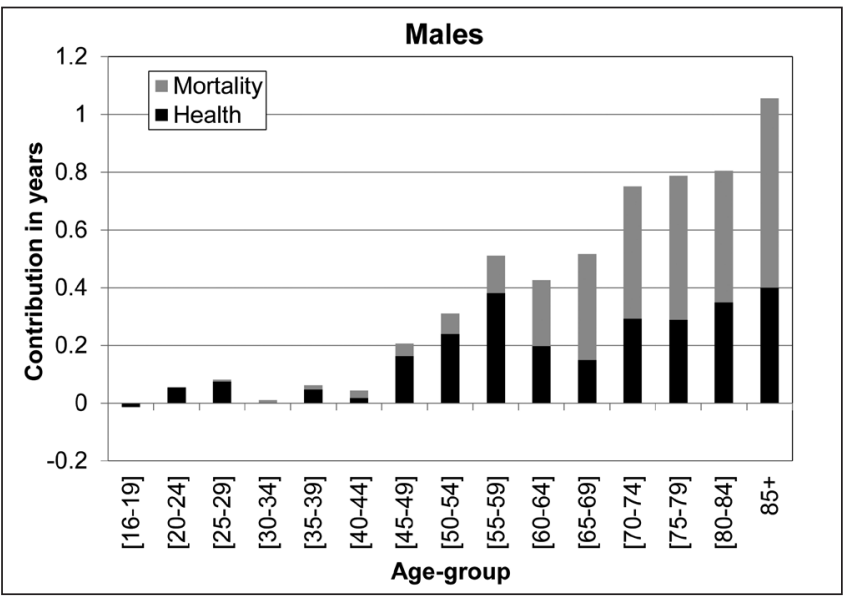

Fig. 4. Decomposition of the difference in Life expectancy in good and fair health between the EU-15 and the Czech Republic, 2010.

Source: EurOhex, EU-SILC 2010 
persons will declare their own perceived health as good, given that other variables are constant. It holds for all tested age-groups and both males and females at the 5\% significance level. A closer look at marital status reveals that when comparing divorced and married individuals, the relative risk for declaring bad health to good health is expected to increase by a factor of 2.1 among both males and females. In terms of fair health status, divorced men and women are also more likely to declare fair health rather than good health, but not all results are statistically significant. Despite statistical insignificance, it seems that gender differences are present for widowed individuals compared to married ones. While widowed women will more likely state fair or bad self-perceived health, widowed men are more likely to declare good self-perceived health. If we pay attention to single men and women in comparison with married individuals, the results are diverse. While single men compared to married men are more likely to declare good health than fair health, for single women compared to married women the regression coefficient has not been found to be statistically different from zero. The obtained results for marital status suggest that married people are better off than divorced and widowed individuals, but it seems less probable that married people perceive their health status differently than single individuals.

In terms of attained education level and income level, the tested model verifies the expected pattern. The higher the education level and the higher the income quartile, the more likely a man or woman will declare their health status as good. On closer examination of attained education, for basic compared to higher education the relative risk for declaring bad health to good health would be expected to increase by a factor 2.4 for males and 6.3 for females. The factor declines as the level of attained education approaches a university degree. Income level approximated by the income quartiles is also highly significant. Men or women who belong to the lower income quartile will more likely denote their own self-perceived health as bad. The factor is higher for males, which could indicate that while income is more important for males, education is more important for women.

It is necessary to note that in spite of the fact that comparative results for males and females differ, during model specification gender was not a significant factor. This could mean that there are no differences in self-perceived health by gender. For the overall model it could be true, but one must take into account that the mechanism leading to that result can significantly differ for men and women (25), which also revealed the decomposition of difference in health expectancies.

\section{CONCLUSION}

This article examines data about self-perceived health in the Czech Republic in the period from 2005-2011. Without a doubt, the life expectancy at birth both for males and females improved significantly in the past two decades in the Czech Republic. This can be ascribed to better population health, but when looking at self-perceived health it is obvious that the Czech Republic is utilizing parameters of healthy life expectancy despite lagging far behind western countries. Decomposition of differences in health expectancies for the Czech Republic and the EU-15 reveals that mortality, rather than a change in self-perceived health status, contributed to the improvement for males, while for females the reverse is true. In addition, a significant improvement in mortality occurred at higher ages both for men and women.

Studying the factors behind the development trends in selfperceived health in the Czech Republic for the year 2011, the regression analysis shows no difference in self-perceived health by gender. Furthermore, results also indicate that there is no difference between the married and single population. However, selfperceived health in married people is better compared to divorced and widowed individuals. The association between income and self-perceived health is also present in the Czech data. Higher income equals a declared better health status. Attained education level seems to be the most influential factor for females. Although self-perceived health can help us understand another dimension of human health, it is necessary to bear in mind that a given category of health is influenced by heterogeneity and cultural factors (28).

\section{Acknowledgement}

The article was supported by the GA CR P404/1/0145 Health and Family - ISSP 2011 a 2012.

\section{Conflict of Interests}

None declared

\section{REFERENCES}

1. Salomon JA, Wang H, Freeman MK, Vos T, Flaxman AD, Lopez AD, et al. Healthy life expectancy for 187 countries, 1990-2010: a systematic analysis for the Global Burden Disease Study 2010. Lancet. 2012 Dec 15;380(9859):2144-62.

2. Moser K, Shkolnikov V, Leon DA. World mortality 1950-2000: divergence replaces convergence from the late 1980s. Bull World Health Organ. 2005 Mar;83(3):202-9.

3. Fries JF. Aging, natural death, and the compression of morbidity. N Engl J Med. 1980 Jul 17;303(3):130-5.

4. Gruenberg EM. The failures of success. Milbank Mem Fund Q Health Soc. 1977 Winter;55(1):3-24.

5. Kramer M. The rising pandemic of mental disorders and associated chronic diseases and disabilities. Acta Psychiatr Scand. 1980;62(Suppl. 285):382-97.

6. Olshansky SJ, Rudberg MA, Carnes BA, Cassel CK, Brody JA. Trading off longer life for worsening health: the expansion of morbidity hypothesis. J Aging Health. 1991;3(2):194-216.

7. Manton KG. Changing concepts of morbidity and mortality in the elderly population. Milbank Mem Fund Q Health Soc. 1982 Spring;60(2):183-244.

8. WHO definition of health [Internet]. Geneva: WHO; c2003 [cited 2014 Dec 8]. Available from: http://www.who.int/about/definition/en/print. html.

9. Hrkal J. English and Czech terms for summary measures of population health. Demografie. 2011;53(3):252-57. (In Czech.)

10. Jagger C, Gillies C, Moscone F, Cambois E, Van Oyen H, Nusselder W, et al; EHLEIS team. Inequalities in healthy life years in the 25 countries of the European Union in 2005: a cross-national meta-regression analysis. Lancet. 2008 Dec 20;372(9656):2124-31.

11. Rychtař́ková J. Healthy life expectancy in the current Czech population. Czech Demogr [Internet]. 2007 [cited 2014 Dec 8];1:61-74. Available from: http://www.czso.cz/csu/2012edicniplan.nsf/t/0F003B33DF/\$File/ demography_2007.pdf.

12. Rychtař́ková J. Disabilityfree life expectancy. Demografie. 2000;42(1):418. (In Czech.)

13. Generation and Gender Programme (GGP). About the Generations and Gender Programme [Internet]. The Hague: NIDI; 2014 [cited 2014 Aug 23]. Available from: http://www.ggp-i.org/about/about-ggp.html.

14. Eurostat. Health status: indicators from the SILC survey (from 2004 onwards) [Internet]. Eurostat; 2013 [cited 2013 Sep 20]. Available 
from: http://epp.eurostat.ec.europa.eu/cache/ITY_SDDS/en/hlth_status silc esms.htm.

15. Hrkal J. Healthy life expectancy in the Czech Republic in 2006. Aktuální informace ÚZIS ČR. 2009(12):1-6.

16. Hrkal J, Kasalová Daňková Š. Healthy life expectancy in the population of the EU. Demografické informační centrum; 2005. (In Czech.)

17. Cambois E, Robine J-M, Brouard N. Life expectancies applied to specific statuses. A history of the indicators and the methods of calculation. Population: An English Selection. 1999;11:7-34

18. Preston SH, Heuveline P, Guillot M. Demography: measuring and modelling population processes. Malden: Blackwell Publishers; 2001.

19. Institut National d'Etudes Demographiques (INED). About REVES [Internet]. INED [cited 2014 Aug 23]. Available from: http://reves.site. ined.fr/en/home/about_reves/.

20. Sullivan DF. A single index of mortality and morbidity. HSMHA Health Rep. 1971 Apr;86(4):347-54

21. Mathers CD, Robine JM. How good is Sullivan's method for monitoring changes in population health expectancies? J Epidemiol Community Health. 1997 Feb;51(1):80-6.

22. Nusselder WJ, Looman CW. Decomposition of differences in health expectancy by cause. Demography. 2004 May;41(2):315-34.

23. Sanders BS. Measuring community health levels. Am J Public Health Nations Health. 1964 Jul;54(7):1063-70.
24. Ministry of Labour and Social Affairs. Pensions [Internet]. Prague: Ministry of Labour and Social Affairs of the Czech Republic [cited 2014 Aug 23]. Available from: http://www.mpsv.cz/en/1606.

25. Hamplová D. Health and marital status: two sides of the same coin? Czech Sociol Rev. 2012;48(4):737-55. (In Czech.)

26. United Nations Educational, Scientific and Cultural Organization. Mediterranean diet [Internet]. Paris: UNESCO [cited 2014 Aug 23]. Available from: http://www.unesco.org/culture/ich/RL/00884

27. Sofi F, Cesari F, Abbate R, Gensini GF, Casini A. Adherence to Mediterranean diet and health status: meta-analysis. BMJ. 2008 Sep 11;337:a1344. doi: 10.1136/bmj.a1344.

28. Šolcová I, Kebza V. Self-rated health: contemporary state of knowledge and results of two Czech studies. Cesk Psychol. 2006;50(1):1-15. (In Czech.)

29. Czech Statistical Office. European Union - Statistics on Income and Living Conditions (EU-SILC) [Internet]. Prague: CZSO [cited 2014 Aug 23]. Available from: http://m.czso.cz/eng/redakce.nsf/i/living_conditions eu_silc/\$File/zp_metodika_20140616_en.pdf.

Received December 13, 2013 Accepted in revised form August 12, 2014 